\title{
Digital record of specimens, including voucher material, from the study of a pollinator habitat restoration site under a commercial solar array in Jackson County, Oregon, 2019.
}

\author{
Maggie Graham ${ }^{\mathrm{a}^{*}}$, Lincoln R. Best ${ }^{\mathrm{b}}$, Andrew R. Moldenke
}

\begin{abstract}
*Corresponding author: margaret.graham@oregonstate.edu
aDepartment of Biological and Ecological Engineering, Oregon State University, Corvallis, OR 97330, USA.

'bepartment of Horticulture, Oregon State University, Corvallis, OR 97330, USA.

'Department of Botany and Plant Pathology, Oregon State University, Corvallis, OR 97330, USA.
\end{abstract}

Cite this work as:

Graham, M., L.R. Best and A.R. Moldenke. 2021. Digital record of specimens, including voucher material, from the study of a pollinator habitat restoration site under a commercial solar array in Jackson County, Oregon, 2019. Catalog of the Oregon State Arthropod Collection. 5(2) 1-2.

DOI: https:// doi.org/10.5399/osu/cat osac.5.2.4855.

\begin{abstract}
Photovoltaic solar energy installation is booming, frequently near agricultural lands. Traditionally, the land underneath ground-mounted photovoltaic panels is unused, though some are repurposing it as habitat for pollinating insects. However, the impact of the solar panel canopy on the pollinator-plant community understory is unknown. In this study (Graham et al., 2020), we investigated the effects of solar arrays on plant composition, bloom timing and foraging behavior of pollinators in open fields (control), and in full shade and partial shade areas under solar panels in a predominant agricultural region of southern Oregon. Pollinating insect specimens were collected using hand nets, and identified to the lowest taxonomic group possible by M. Graham, A.R. Moldenke, and L.R. Best. A total of 85 voucher specimens were deposited into the Oregon State Arthropod Collection; accession record: OSAC_AC_2021_03_11_001-01.
\end{abstract}

\section{Description of Collection}

During the summer of 2019, we inventoried pollinating insects at the Eagle Point Solar Plant, a commercial solar facility in Jackson County, Oregon, as part of a study on plant-pollinator interactions in agrivoltaic systems (Graham et al., 2020). In total, we sampled 458 insects using hand nets. Surveys lasted 30 minutes, spanned a $100 \mathrm{~m}^{2}$ area, and were repeated eight times from May to September at approximately 2 week intervals. Sampling occurred between 9 am and 4 pm, on warm $\left(>16^{\circ} \mathrm{C}\right)$, calm $(<20 \mathrm{~km} / \mathrm{h}$ wind $)$ days. Surveys occurred at 3 distinct locations (blocks) throughout the solar facility. Each block was partitioned into three treatment areas, one fully shaded (5\% full sun) by the solar panels, one partially shaded (75\% full sun), and one located in full sun (control). Because of a maintenance issue, blocks $\mathrm{A}, \mathrm{B}$, and $\mathrm{C}$ were used during the first week of the survey, and blocks B, C, and D were used during weeks $2-8$ of the survey. Only records from weeks 2-8 of the survey were used for statistical analysis (Graham et al. 2021). Full sun and partial sun plots were surveyed when plots were unshaded. Unshaded surveys were not possible in full shade plots, which were surveyed when shaded. We collected all insects observed touching the reproductive parts of flowers, excluding individuals from the family Miridae, which were found in large quantities on stems, leaves, and flowers of some plants. After netting, we placed insects in ethyl acetate jars and froze for later identification. 
We pinned, sexed, and identified bee specimens to genus using keys produced for the CAMPOLIN bee course (2012) and Michener et al., 2007. When possible, we determined species-level identifications for Bombus using: Williams et al. 2008 and Williams et al., 2014, and for Halictus using: Roberts, 1973. Other pollinating insects were sorted to order or family where possible. Ladybugs (Coccinella and Hippocampus) and leaf beetles (Diabrotica) were identified to species with the website (www.discoverlife.org). These identifications were confirmed, and additional identifications made, by L.R. Best and / or A.R. Moldenke and checked with voucher specimens at the Oregon State Arthropod Collection, Department of Integrative Biology, Oregon State University, Corvallis, OR. Taxonomic names were confirmed with the GBIF name matcher (https:/ / www.gbif.org/tools/ species-lookup).

We collected a total of 458 insect specimens, representing five orders and 65 species of insects. The observation records for these specimens were made public via an IPT and can be accessed at www. gbif.org, and a copy of those records is archived as a text file (csv) attached to this publication. One voucher specimen was selected for each sex of each species collected, amounting to total of 85 voucher specimens, which were deposited into the Oregon State Arthropod Collection; accession record: OSAC_AC_2021_03_11_001-01.

\section{Acknowledgements}

This research was supported in part by the Agricultural Research Foundation of Oregon State University and NSF Grant \#1740082. Additionally, the authors would like to thank the staff and volunteers of the Oregon Bee Project, Sean and Kathryn Prive, John Jacob, Mary Alice Coulter, 1000 Friends of Oregon, and Pine Gate Renewables for their support of this project

\section{References}

CANPOLIN Bee Course. 2012. Key to Bee Genera in Canada. CANPOLIN. http://www.uoguelph.ca/canpolin.

Graham, M., A. Ates, A.P. Melathopoulos, A.R. Moldenke, S.J. DeBano, L.R. Best and C.H. Higgins. 2021. Partial shading by solar panels delays bloom, increases floral abundance during the late-season for pollinators in a dryland, agrivoltaic ecosystem. Scientific Reports. 11 (7452). 10.1038/s41598-021-86756-4

Michener, C.D. 2007. The Bees of the World. The Johns Hopkins University Press.

Roberts, R. B. 1973. Bees of Northwestern America: HALICTUS (Hymenoptera: Halictidae). Oregon State University Agricultural Experiment Station.

Williams, P. H., S.A. Cameron, H.M. Hines, B. Cederberg and P.A. Rasmont. 2008. A simplified subgeneric classification of the bumblebees (genus Bombus). Apidologie 39, 46-74.

Williams, P. H., R.W. Thorp, L.L. Richardson and S.R. Colla. 2014. Bumble bees of North America: an identification guide. Princeton University Press. 